\title{
Ni-Mn-Sn-Cu Alloys after Thermal Cycling: Thermal and Magnetic Response
}

\author{
Asma Wederni ${ }^{1}$, Mihail Ipatov ${ }^{2}$, Julián-María González ${ }^{2}$, Mohamed Khitouni ${ }^{3}$ and Joan-Josep Suñol ${ }^{1, *(1)}$ \\ 1 Department of Physics, P2, EPS, University of Girona, 17003 Girona, Spain; asma.wederni@gmail.com \\ 2 Department of Applied Physics, University of the Basque Country, 20018 Donostia, Spain; \\ mihail.ipatov@ehu.es (M.I.); julianmaria.gonzalez@ehu.es (J.-M.G.) \\ 3 Laboratory of Inorganic Chemistry, University of Sfax, B.P. 1171, Sfax 3000, Tunisia; \\ mohamed.khitouni@fss.rnu.tn \\ * Correspondence: joanjosep.sunyol@udg.edu; Tel.: +34-972419757
}

check for updates

Citation: Wederni, A.; Ipatov, M.; González, J.-M.; Khitouni, M.; Suñol, J.-J. Ni-Mn-Sn-Cu Alloys after Thermal Cycling: Thermal and Magnetic Response. Materials 2021, 14, 6851. https://doi.org/10.3390/ ma14226851

Academic Editor: Adam Grajcar

Received: 14 October 2021

Accepted: 10 November 2021

Published: 13 November 2021

Publisher's Note: MDPI stays neutral with regard to jurisdictional claims in published maps and institutional affiliations.

Copyright: (c) 2021 by the authors. Licensee MDPI, Basel, Switzerland. This article is an open access article distributed under the terms and conditions of the Creative Commons Attribution (CC BY) license (https:// creativecommons.org/licenses/by/ $4.0 /)$.

\begin{abstract}
Heusler Ni-Mn-Sn-based alloys are good candidates for magnetic refrigeration. This application is based on cycling processes. In this work, thermal cycles (100) have been performed in three ribbons produced by melt-spinning to check the thermal stability and the magnetic response. After cycling, the temperatures were slowly shifted and the thermodynamic properties were reduced, the entropy changed at about 3-5\%. Likewise, the thermomagnetic response remains similar. Thus, these candidates maintain enough thermal stability and magnetic response after cycling. Likewise, $\mathrm{Cu}$ addition shifts the structural transformation to higher temperatures, whereas the Curie temperature is always near $310 \mathrm{~K}$. Regarding magnetic shape memory applications, the best candidate is the $\mathrm{Ni}_{49} \mathrm{Mn}_{36} \mathrm{Sn}_{14} \mathrm{Cu}_{1}$ alloy.
\end{abstract}

Keywords: Heusler; thermal cycling; thermal analysis; magnetic behavior

\section{Introduction}

Ni-Mn-Sn-based Heusler ferromagnetic alloys are multifunctional materials due to the coupling of a reversible solid-state first order transformation (austenite to martensite) and a second order magnetic transformation (ferromagnetic to paramagnetic). In these alloys, the transformations can be induced by mechanical stress, temperature and/or external magnetic field. Functional effects of these materials are: magnetic shape memory [1], magnetocaloric [2], magneto-resistance [3], exchange-bias [4], barocaloric [5] or elastocaloric [6].

Addition of small quantities of a fourth element in the ternary off-stoichiometry Heusler alloys has been proposed as a way to improve the functional response and to tailor the transition temperatures [7]. The shift of the transition temperatures is due to the sensitivity to interatomic distances and hybridization [8]. This trend opens the possibility of deliberate changes in the transition temperatures and benefits while forcing phase transitions by a temperature and magnetic field [9]. The improvement of the magnetic response could be favored by the addition of a magnetic element as Fe [10] or Co [11]. Gd-based and Ni-Mn-In alloys are good candidates for magnetic refrigeration devices. Thus, Gd [12] or In [13] addition has been also analyzed. A minor amount of other metallic elements, such as Zn [14], Al [15] or Pd [16], or metalloids, such as B [17] have been also checked. In these compounds, the main effect is the shift of the transition temperatures. Obviously, the addition of two elements to combine their effect has been done, such as $\mathrm{Pt}$ and Co [18]. In our work, $\mathrm{Cu}$ addition has been performed.

Likewise, for the magnetic refrigeration or shape memory applications it is necessary to check the stability of the functional response after cycling. The mechanical cycling from $\mathrm{Ni}-\mathrm{Mn}$-based alloys shows that the mechanical stability is linked to the good geometrical compatibility at the interphase between austenite and martensite [19]. 
In our study, we produce three Ni-Mn-Sn-(Cu) Heusler alloys. In a previous work [20], we analyzed the microstructure of the as produced ribbons as well as the thermal and magnetic behavior. These ribbon flakes have been now subjected to controlled thermal cycling (100 cycles). The main objective is to analyze the thermal and magnetic response to check its thermal and magnetic stability after cycling.

\section{Materials and Methods}

Three alloys with nominal composition (at.\%) $\mathrm{Ni}_{50-x} \mathrm{Mn}_{36} \mathrm{Sn}_{14} \mathrm{Cu}_{x}(x=0,1$, and 2) were produced by melt-spinning (melt-spinner MSP 10, Edmund Bühler GmbH, Bodelshausen, Germany) as ribbon flakes ( $1 \mathrm{~mm}$ thick, $2-3 \mathrm{~cm}$ long, $20 \mu \mathrm{m}$ width). The X-ray diffraction (XRD, D500 S equipment, Bruker, Billerica, MA, USA) patterns at room temperature were made to verify the crystallographic structure of the spun-ribbons. The refinement of crystalline structures were made by applying the Maud software, which is founded on the Rietveld method [11]. Austenite to martensite direct and inverse temperatures were determined by differential scanning calorimetry (DSC) in a DSC822 Mettler-Toledo calorimeter, at a heating/cooling rate of $10 \mathrm{~K} / \mathrm{min}$. Thermal cycling (100 cycles) experiments were performed with liquid nitrogen between nitrogen liquidus temperature and room temperature. Thermomagnetic measurements were done on a PPMS 6000 device (Quantum Design, San Diego, CA, USA). Zero-field-cooling (ZFC), field-cooling (FC) and field-heating $(\mathrm{FH})$ protocols, in a temperature range from low temperature up to $400 \mathrm{~K}$ and an applied magnetic field up to $50 \mathrm{kOe}$; whereas magnetic hysteresis loops were recorded at $50 \mathrm{~K}$ and $300 \mathrm{~K}$.

\section{Results and Discussion}

The results include the crystallographic analysis of the as-quenched ribbon flakes and the analysis of the thermal and magnetic behavior after cycling. These results were discussed by comparison with those of ribbons before thermal cycling.

\subsection{Crystallographic Analysis}

The analysis of the three diffraction patters collected by XRD of the ribbons shows that at room temperature all the samples have a cubic L $2_{1}$ Heusler structure. This crystallographic structure is found in ternary alloys and the stoichiometry is 2:1:1 $\left(\mathrm{X}_{2} \mathrm{YZ}\right)$. Thus, we produce of stoichiometry alloys, and the excess od Mn atoms will be in $\mathrm{Z}$ sites. The Rietveld analysis has been performed, as shown in the Figure 1.

The $\mathrm{L} 2{ }_{1}$ orders have been determined by taking into account Equation (1):

$$
\left(\mathrm{I}_{111} / \mathrm{I}_{220}\right)_{\exp }=\left[\mathrm{S}_{\mathrm{L} 21}\left(3-\mathrm{S}_{\mathrm{B} 2} / 2\right)\right]^{2}\left(\mathrm{I}_{111} / \mathrm{I}_{220}\right)_{\mathrm{th}},
$$

where the I (hkl) refers to the Bragg peak's intensity, Miller indices (hkl) and the suffixes 'exp' represent experimentally obtained intensity values and "th" represents theoretically simulated and " $\mathrm{S}$ " represents the order parameter. This order parameter before cycling ranged between $85-88 \%$ [20], whereas between $73-75 \%$ after cycling. The produced alloys were off-stoichiometry. Thus, this reduction indicates that the alloys evolve to the lower expected $\mathrm{L} 2{ }_{1}$ order.

The crystallographic parameters derived from Rietveld analysis of the specimens before and after thermal cycling are given in Table 1. 

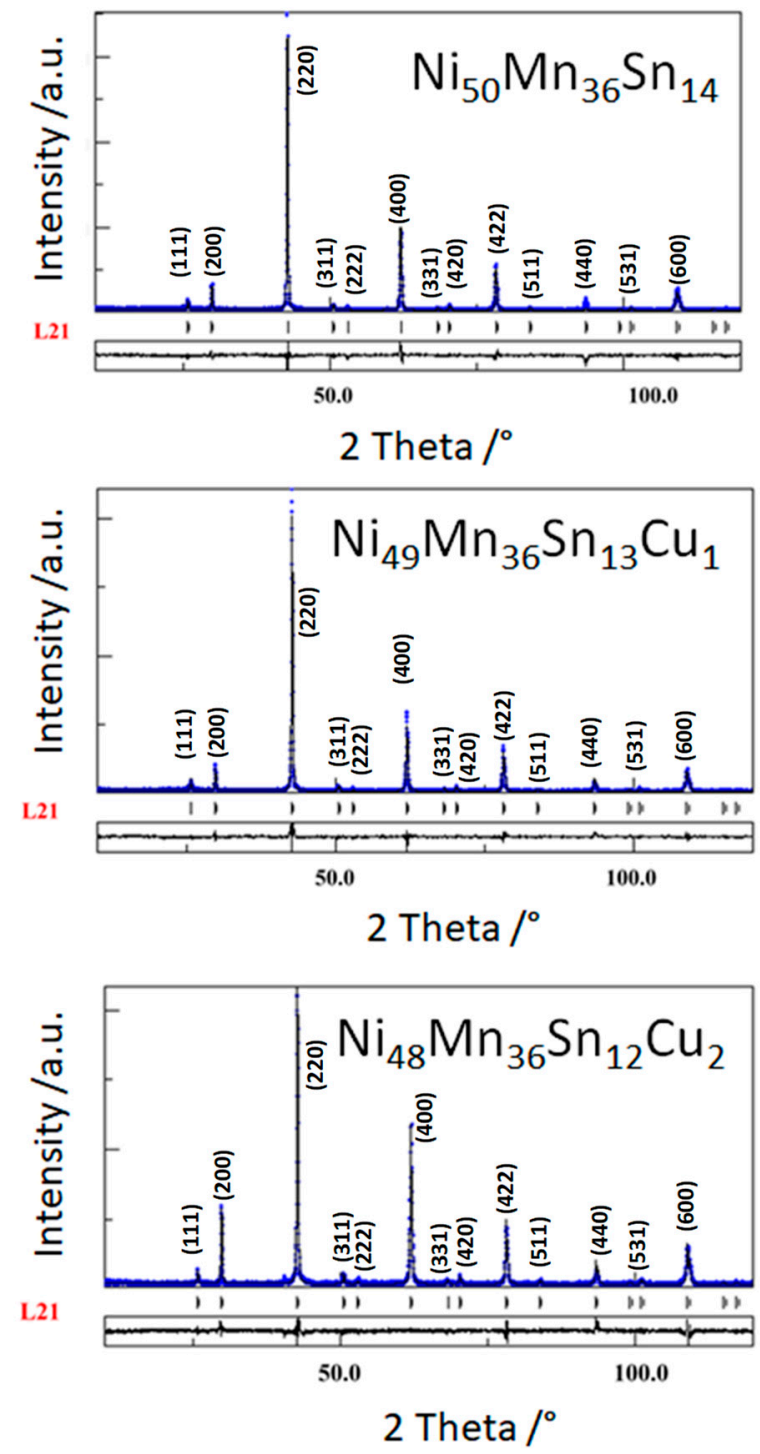

Figure 1. X-ray diffraction patterns of the Ni-Mn-Sn-(Cu) ribbons.

Table 1. Crystallographic parameters obtained from XRD analysis of specimens before and after thermal cycling.

\begin{tabular}{cccc}
\hline Alloy & $\begin{array}{c}\text { Lattice } \\
\text { Parameter/nm }\end{array}$ & Microstrain/\% & Crystallite Size/nm \\
\hline $\mathrm{Ni}_{50} \mathrm{Mn}_{36} \mathrm{Sn}_{14}$ (before) & $\mathrm{a}=0.5983$ & 0.650 & 114 \\
$\mathrm{Ni}_{50} \mathrm{Mn}_{36} \mathrm{Sn}_{14}$ (after) & $\mathrm{a}=0.5981$ & 0.583 & 127 \\
$\mathrm{Ni}_{49} \mathrm{Mn}_{36} \mathrm{Sn}_{14} \mathrm{Cu}_{1}$ (before) & $\mathrm{a}=0.5980$ & 0.643 & 103 \\
$\mathrm{Ni}_{49} \mathrm{Mn}_{36} \mathrm{Sn}_{14} \mathrm{Cu}_{1}$ (after) & $\mathrm{a}=0.5987$ & 0.536 & 125 \\
$\mathrm{Ni}_{48} \mathrm{Mn}_{36} \mathrm{Sn}_{44} \mathrm{Cu}_{2}$ (before) & $\mathrm{a}=0.5982$ & 0.928 & 82 \\
$\mathrm{Ni}_{48} \mathrm{Mn}_{36} \mathrm{Sn}_{14} \mathrm{Cu}_{2}$ (after) & $\mathrm{a}=0.5992$ & 0.853 & 94 \\
\hline
\end{tabular}

The lattice parameters change slightly with the thermal cycling and/or the Cu addition. Meanwhile, the microstrain decreases after cycling and the crystalline size increases. Probably the local atomic displacements during cycling and the accommodation of the martensite favors this behavior.

\subsection{Thermal Analysis}

As the crystallographic phase is cubic at room temperature, in all samples only the austenite phase is detected. In order to determine the temperatures of the reversible austen- 
ite to martensite structural transformation continuous cooling-heating was performed. Figures $2-4$ show the DSC scans before and after thermal cycling of alloys $\mathrm{Ni}_{50-x} \mathrm{Mn}_{36}$ $\mathrm{Sn}_{14} \mathrm{Cu}_{\mathrm{x}}(x=0,1$, and 2$)$, respectively.

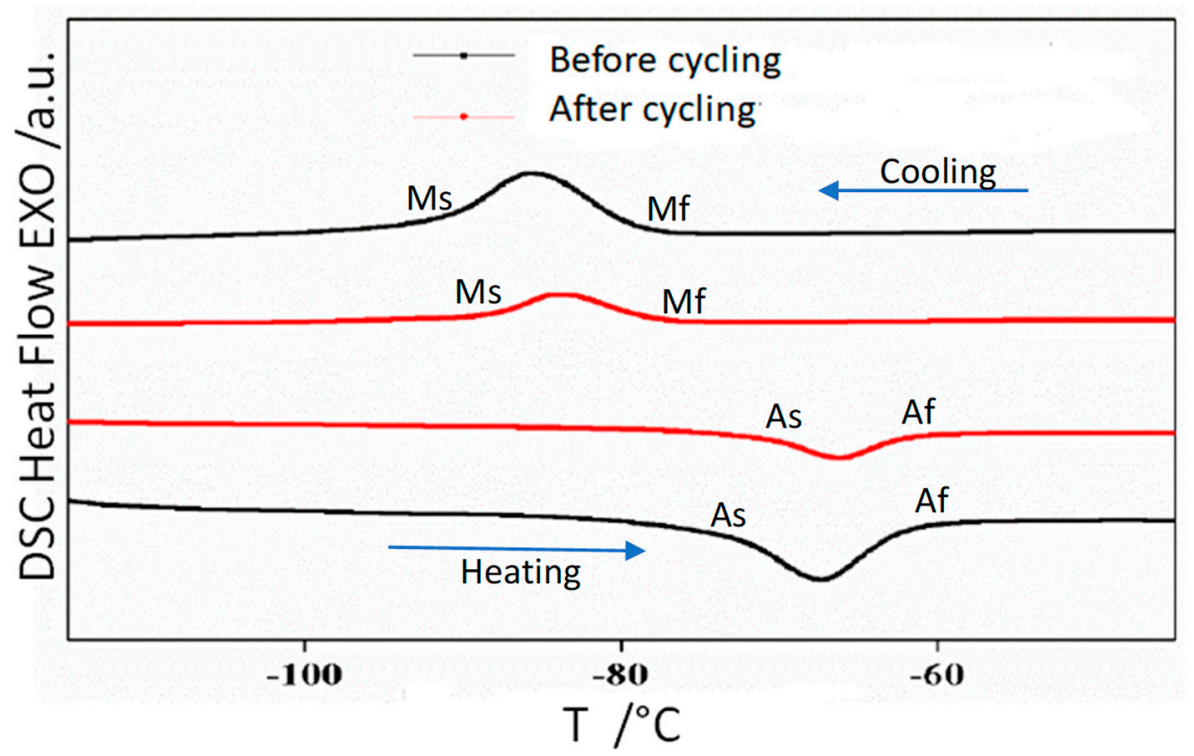

Figure 2. DSC reversible scans of alloy $\mathrm{Ni}_{50} \mathrm{Mn}_{36} \mathrm{Sn}_{14}$ before and after 100 thermal cycles.

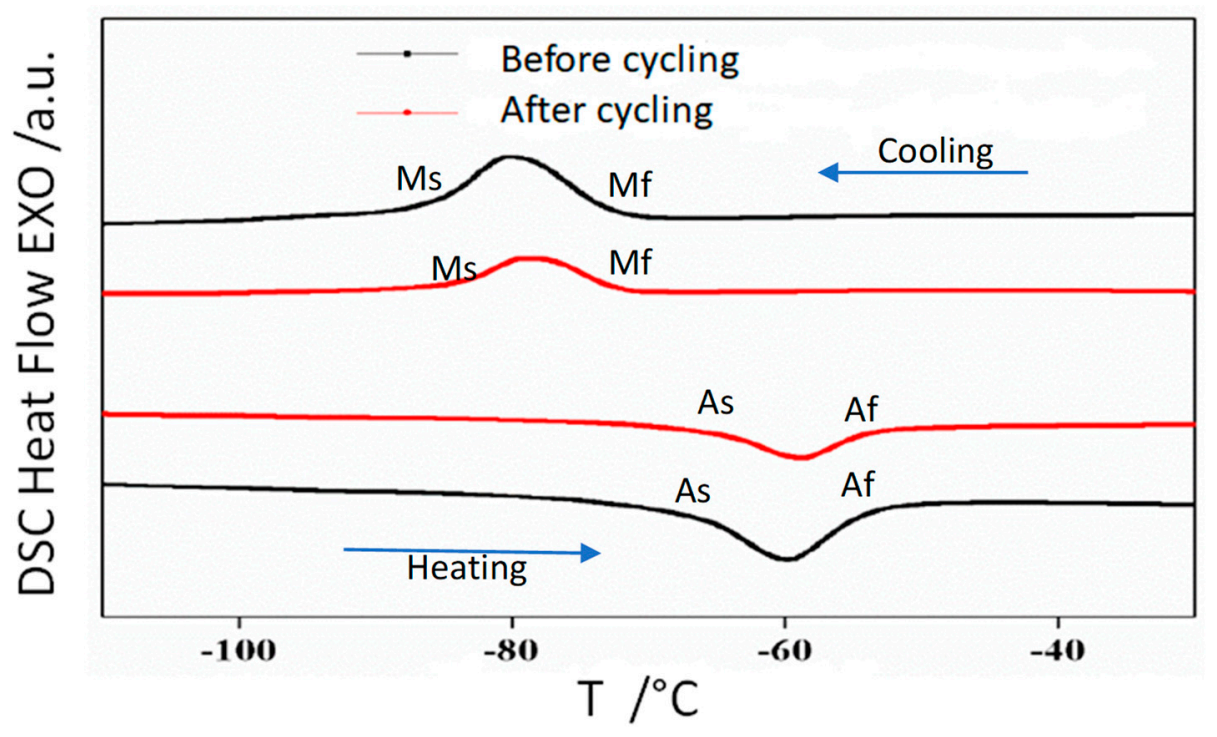

Figure 3. DSC reversible scans of alloy $\mathrm{Ni}_{49} \mathrm{Mn}_{36} \mathrm{Sn}_{14} \mathrm{Cu}_{1}$ before and after 100 thermal cycles.

The scans show that the addition of a minor amount of $\mathrm{Cu}$ shifts the transition temperatures to higher values. Thus, by controlling composition it is possible to design the production of alloys with transformation temperatures close to room temperature. A characteristic temperature is the equilibrium Gibbs temperature of the martensite structural transformation, $\mathrm{T}_{0}$, that is calculated from DSC scan analysis following the procedure described in reference [21]. The $T_{0}$ values obtained before and after thermal cycling are provided in Table 2 . Thermal cycling slightly increases the transformation temperatures. 


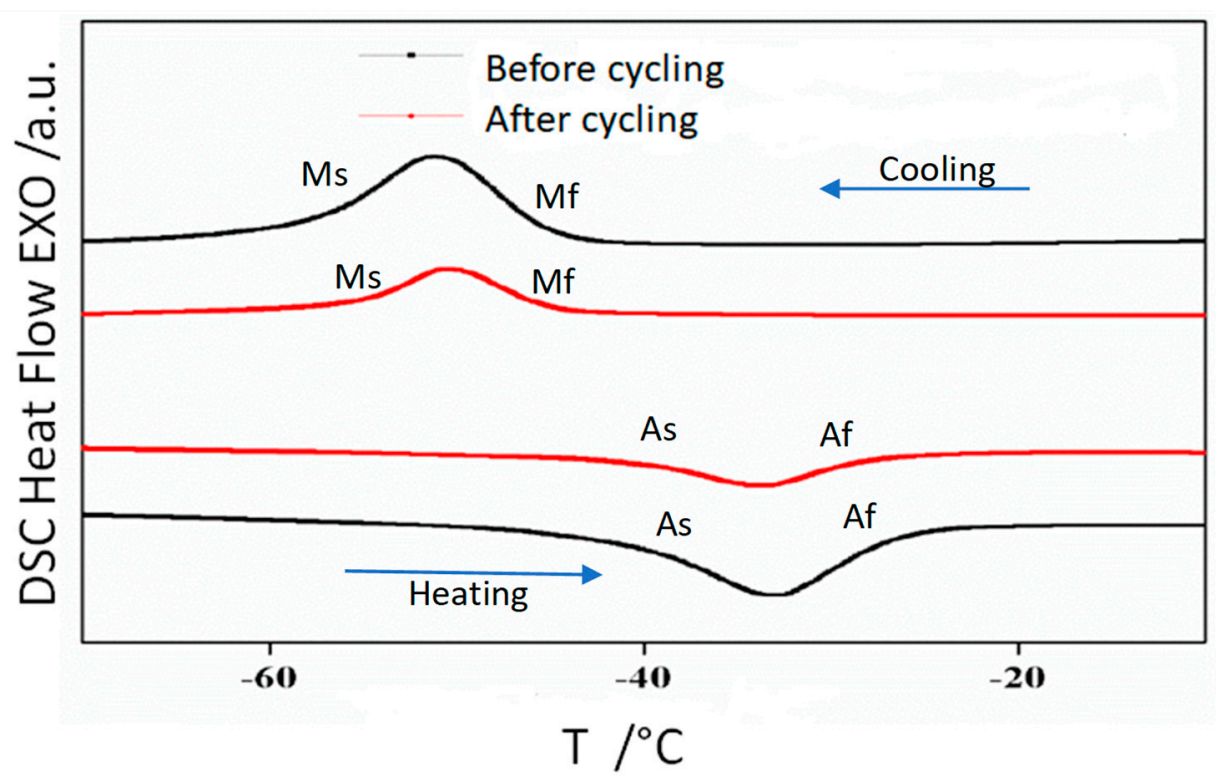

Figure 4. DSC reversible scans of alloy $\mathrm{Ni}_{48} \mathrm{Mn}_{36} \mathrm{Sn}_{14} \mathrm{Cu}_{2}$ before and after 100 thermal cycles.

Table 2. Equilibrium Gibbs temperature, $\mathrm{T}_{\mathrm{O}}$, and thermodynamic parameters (enthalpy $\Delta \mathrm{H}$, entropy, $\Delta S$ ) of the structural transformation before and after thermal cycling (before values are calculated following the procedure and data provided in reference [21]). $T_{o}$ is one half of $M_{s}+A_{f}$.

\begin{tabular}{cccc}
\hline Alloy & $\mathbf{T}_{\mathbf{o}} / \mathbf{K}$ & $\boldsymbol{\Delta H} / \mathbf{J ~ g}^{-\mathbf{1}}$ & $\Delta \mathbf{S} / \mathbf{J} \mathbf{~ g}^{-\mathbf{1}} \mathbf{K}^{-\mathbf{1}}$ \\
\hline $\mathrm{Ni}_{50} \mathrm{Mn}_{36} \mathrm{Sn}_{14}$ (before) & 203.2 & 1.54 & 0.0077 \\
$\mathrm{Ni}_{50} \mathrm{Mn}_{36} \mathrm{Sn}_{14}$ (after) & 204.4 & 1.44 & 0.0073 \\
$\mathrm{Ni}_{49} \mathrm{Mn}_{36} \mathrm{Sn}_{14} \mathrm{Cu}_{1}$ (before) & 211.5 & 1.61 & 0.0079 \\
$\mathrm{Ni}_{49} \mathrm{Mn}_{36} \mathrm{Sn}_{14} \mathrm{Cu}_{1}$ (after) & 212.4 & 1.60 & 0.0077 \\
$\mathrm{Ni}_{48} \mathrm{Mn}_{36} \mathrm{Sn}_{14} \mathrm{Cu}_{2}$ (before) & 237.0 & 2.53 & 0.0100 \\
$\mathrm{Ni}_{48} \mathrm{Mn}_{36} \mathrm{Sn}_{14} \mathrm{Cu}_{2}$ (after) & 238.2 & 2.27 & 0.0096 \\
\hline
\end{tabular}

The enthalpy and entropy values of the structural transformation $(\Delta \mathrm{H}$ and $\Delta \mathrm{S}$ respectively) are also given in Table 1 . The enthalpy decreases with thermal cycling, the same effect is found in the entropy. These trends need to be confirmed for long term cycles and should be taken into account in the design of magnetocaloric devices.

\subsection{Magnetic Analysis}

Further, we will consider the magnetic properties of the alloys. Zero-field-cooling (ZFC), field-heating (FH), and field-cooling (FC) experiments have been performed at two different external magnetic fields to check the magnetic response at low (50 Oe) and high (50 KOe) magnetic fields. The thermomagnetic curves are represented in Figures 5-7 for thermally cycled alloys $\mathrm{Ni}_{50-x} \mathrm{Mn}_{36} \mathrm{Sn}_{14} \mathrm{Cu}_{\mathrm{x}}(x=0,1$, and 2), respectively.

As expected, through the process of the structural transition at 50 Oe, both FC and ZFC curves exhibit an irreversible behavior due to the obvious hysteresis between FC and ZFC curves, leading to the direct and inverse martensite transformation. It is known that this transformation requires overheating (martensite to austenite) and undercooling (austenite to martensite). This behavior was presented in such a thermal hysteresis between the FH and FC curves. Furthermore, the separation between the ZFC and FC scans below this ferromagnetic transition usually caused by spin glass state and/or the coexistence of antiferromagnetic and ferromagnetic states [22,23]. 

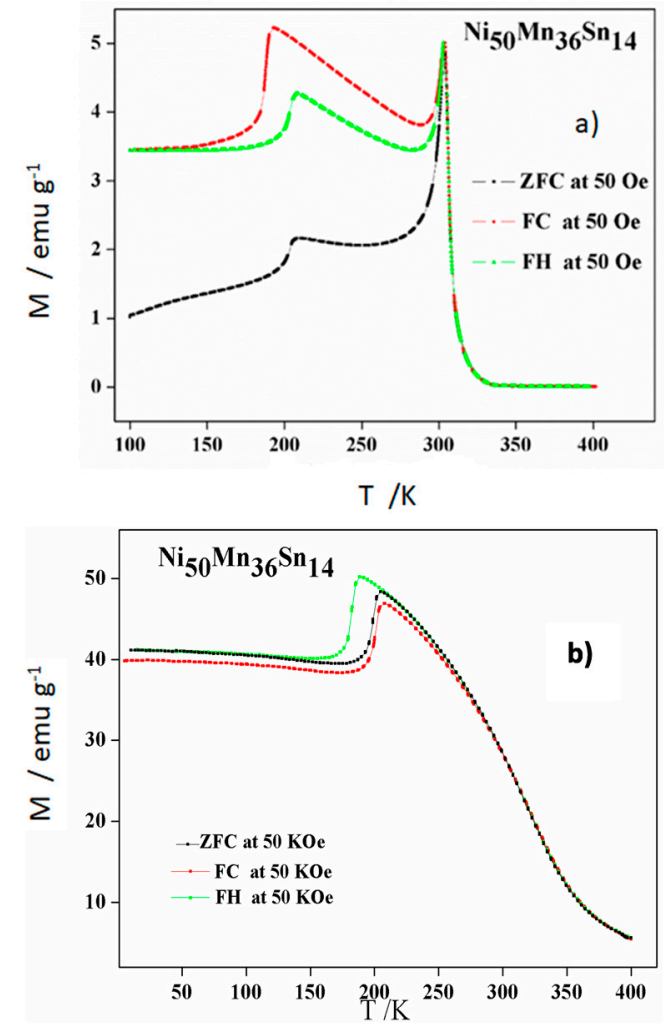

Figure 5. ZFC, FH, and FC thermomagnetic measurements of alloy $\mathrm{Ni}_{50} \mathrm{Mn}_{36} \mathrm{Sn}_{14} \cdot$ (a) 50 Oe and (b) 50 KOe.

Regarding the influence of the $\mathrm{Cu}$ addition, it is clear that the $\mathrm{Cu}$ favors the increase of the temperatures of the structural transformation, confirming DSC data, whereas the Curie temperature remains early constant at around $310 \mathrm{~K}$. Thus, this temperature was slightly increased (3-5 K) after thermal cycling [20]. The first effect was also detected in the samples before thermal cycling, whereas a slight decrease (up to $13 \mathrm{~K}$ ) was found in the Curie temperature. From the results after cycling, we can remark that $\mathrm{Cu}$ addition could be a way to shift the structural transformation close to the magnetic transformation in order to favor the interplay between both transformations at low magnetic fields. It is well known that the total entropy change, $\Delta S$, linked to the martensite transformation represents a limit to the attainable magnetic entropy change, and it has been phenomenologically established that it decreases exponentially with the increment of the generalized order parameter defined as the temperature interval between the Curie temperature of the austenite and the Gibbs equilibrium temperature of the structural transformation, $\mathrm{T}_{C}-\mathrm{T}_{\mathrm{O}}$ [10]. From such relation, it can be deduced that the closest the Curie temperature of the austenite to the equilibrium temperature, the largest the magnetic entropy change values can be achieved. Likewise, at 50 Oe the magnetization has a minor growth as $\mathrm{Cu}$ content increases. This tendency is not followed at $50 \mathrm{kOe}, 1$ at.\% $\mathrm{Cu}$ addition increases magnetization, but 2 at. $\% \mathrm{Cu}$ addition does not. 

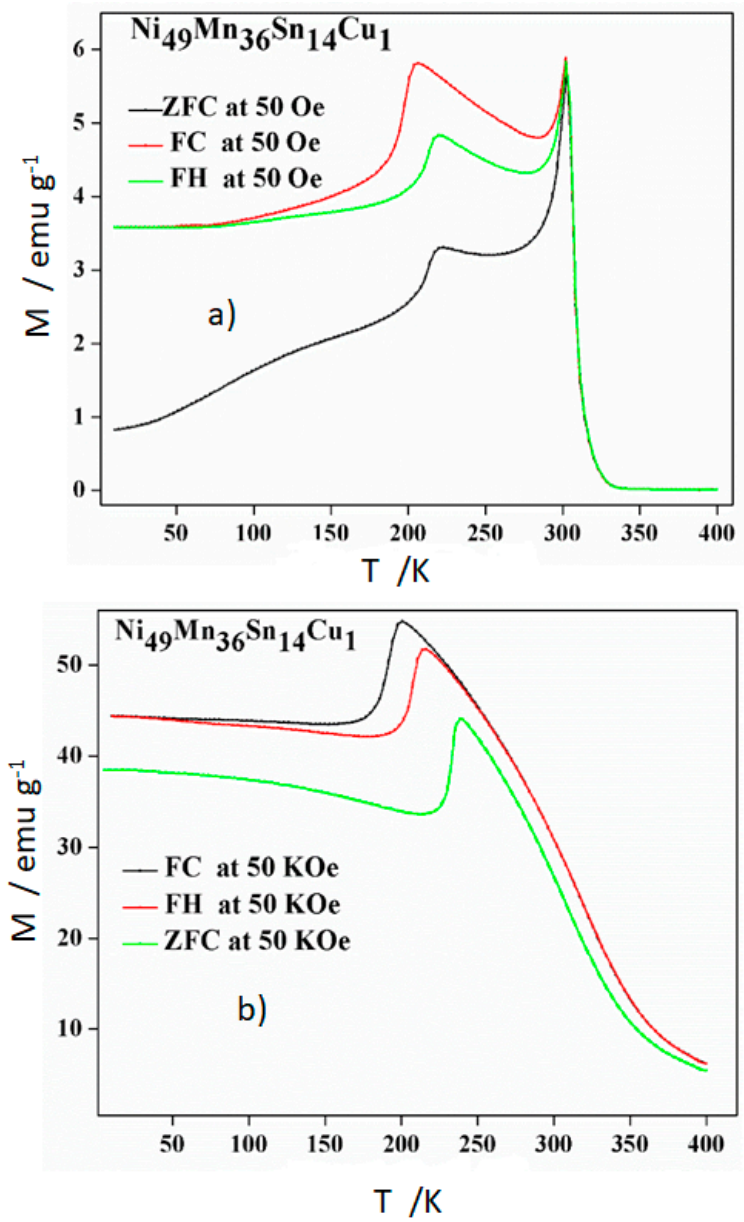

Figure 6. ZFC, FH and FC thermomagnetic measurements of alloy $\mathrm{Ni}_{49} \mathrm{Mn}_{36} \mathrm{Sn}_{14} \mathrm{Cu}_{1}$. (a) 50 Oe and (b) $50 \mathrm{KOe}$.

Furthermore, one can note that the martensite is more stable when increasing the applied magnetic field because in the alloy without $\mathrm{Cu}$, it takes more energy to transform the austenite into martensite. The important shift in the temperatures of the structural transformation by the $\mathrm{Cu}$ addition detected in DSC scans is reduced in the thermomagnetic scans at $50 \mathrm{kOe}$. Thus, for the possible applications of these alloys it is important to analyse their magnetic response at the expected working magnetic field.

It is known that the increase of the magnetization shift between the martensitic and the austenite phases benefits the field induced phase transformation, especially close to temperatures close the austenite start formation [7]. In our study, an increase of the magnetization change was found as increasing $\mathrm{Cu}$ content, it is a signal that the energy difference between the austenite $\mathrm{L} 2{ }_{1}$ structure and the martensite structure increases by $\mathrm{Cu}$ doping [24]. Likewise, the calculated values of the temperature change due to an applied magnetic field of $1 \mathrm{~T}$ were 1.10, 1.30 and $1.16 \mathrm{~K} / \mathrm{T}$ for the alloys with $\mathrm{x}=0,1$, and 2 at.\% of $\mathrm{Cu}$, respectively. These values are slightly different than the calculated for the same specimens before thermal cycling: 1.28, 1.29, and $1.11 \mathrm{~K} / \mathrm{T}$. As there are close compositions, it is expected that the martensite phase was modulated $10 \mathrm{M}$, as previously found in reference [20]. 

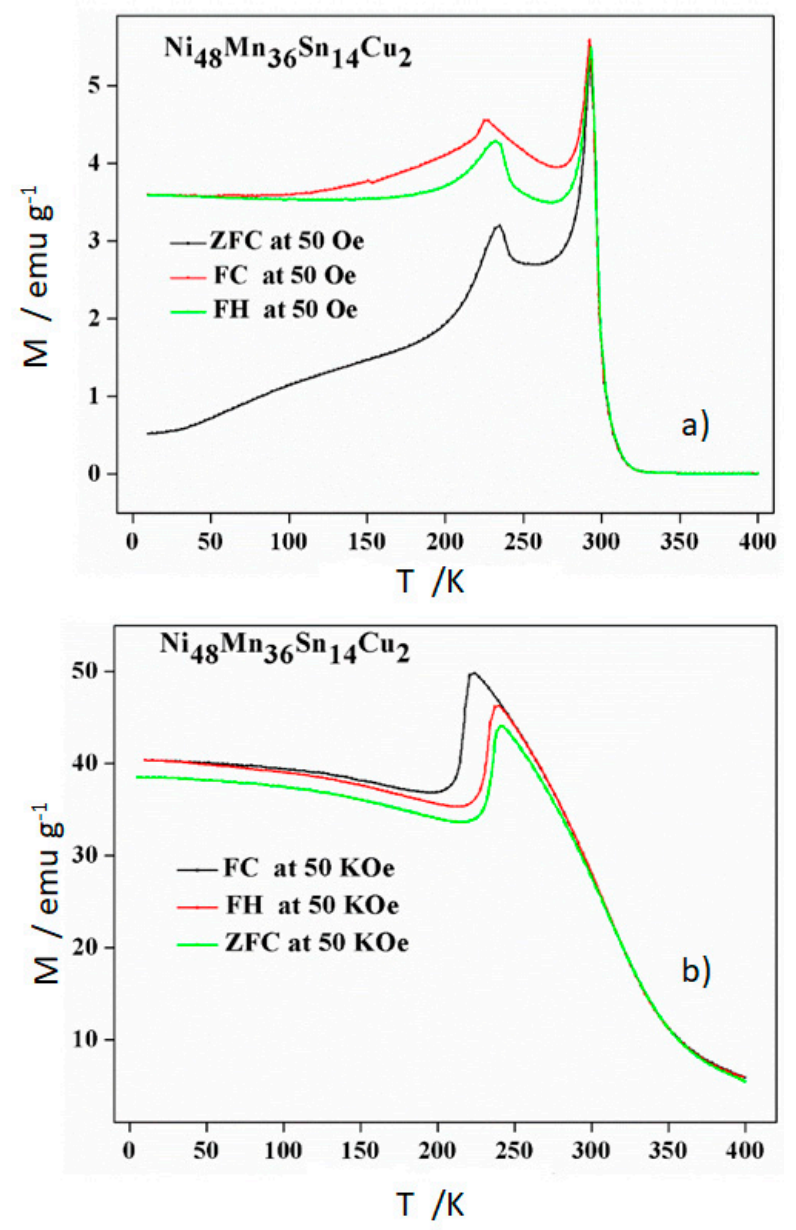

Figure 7. ZFC, FH, and FC thermomagnetic measurements of alloy $\mathrm{Ni}_{48} \mathrm{Mn}_{36} \mathrm{Sn}_{14} \mathrm{Cu}_{2}$. (a) 50 Oe and (b) 50 KOe.

It can be concluded that the best alloy for applications linked to the magnetic shape memory and magnetocaloric effects is $\mathrm{Ni}_{49} \mathrm{Mn}_{36} \mathrm{Sn}_{14} \mathrm{Cu}_{1}$, as the elastocaloric behavior [25]. The non-continuous variation (as a function of $\mathrm{Cu}$ content) may be caused by hybridization or the non-entirely ferromagnetic band splitting [24].

Complementary magnetic analysis has been performed by performing magnetic hysteresis loops ( $50 \mathrm{~K}$ and $300 \mathrm{~K}$ ). The results are shown in the Figure 8.

All the hysteresis loops at $50 \mathrm{~K}$ are clearly ferromagnetic. The measurements at $300 \mathrm{~K}$ show the decrease of the magnetization of saturation and the coercivity. The $\mathrm{Cu}$ addition provokes an increase in the coercivity and minor changes in the magnetization of saturation. The results are given in Table 3 and are similar to those obtained before thermal cycling. The increase on the coercivity with the increase of the $\mathrm{Cu}$ content can be provoked by the higher microstrain (Table 1 data).

Table 3. Magnetic parameters derived from Figure 8 hysteresis loops.

\begin{tabular}{ccccc}
\hline Alloy & $\begin{array}{c}\text { Saturation } \\
\text { Magnetization } \\
(\mathbf{e m u} / \mathbf{g}) \text { at } \mathbf{5 0 ~ K}\end{array}$ & $\begin{array}{c}\text { Saturation } \\
\text { Magnetization } \\
(\mathbf{e m u} / \mathbf{g}) \text { at } \mathbf{3 0 0 ~ \mathbf { ~ K }}\end{array}$ & $\begin{array}{c}\text { Coercivity } \\
(\mathbf{O e}) \text { at } \mathbf{5 0 ~ K}\end{array}$ & $\begin{array}{c}\text { Coercivity (Oe) } \\
\text { at 300 K }\end{array}$ \\
\hline $\mathrm{Ni}_{50} \mathrm{Mn}_{36} \mathrm{Sn}_{14}$ & 38.5 & 19.5 & 266 & 10.2 \\
$\mathrm{Ni}_{49} \mathrm{Mn}_{36} \mathrm{Sn}_{14} \mathrm{Cu}_{1}$ & 40.0 & 21.5 & 275 & 10.0 \\
$\mathrm{Ni}_{48} \mathrm{Mn}_{36} \mathrm{Sn}_{14} \mathrm{Cu}_{2}$ & 38.6 & 18.8 & 400 & 11.6 \\
\hline
\end{tabular}



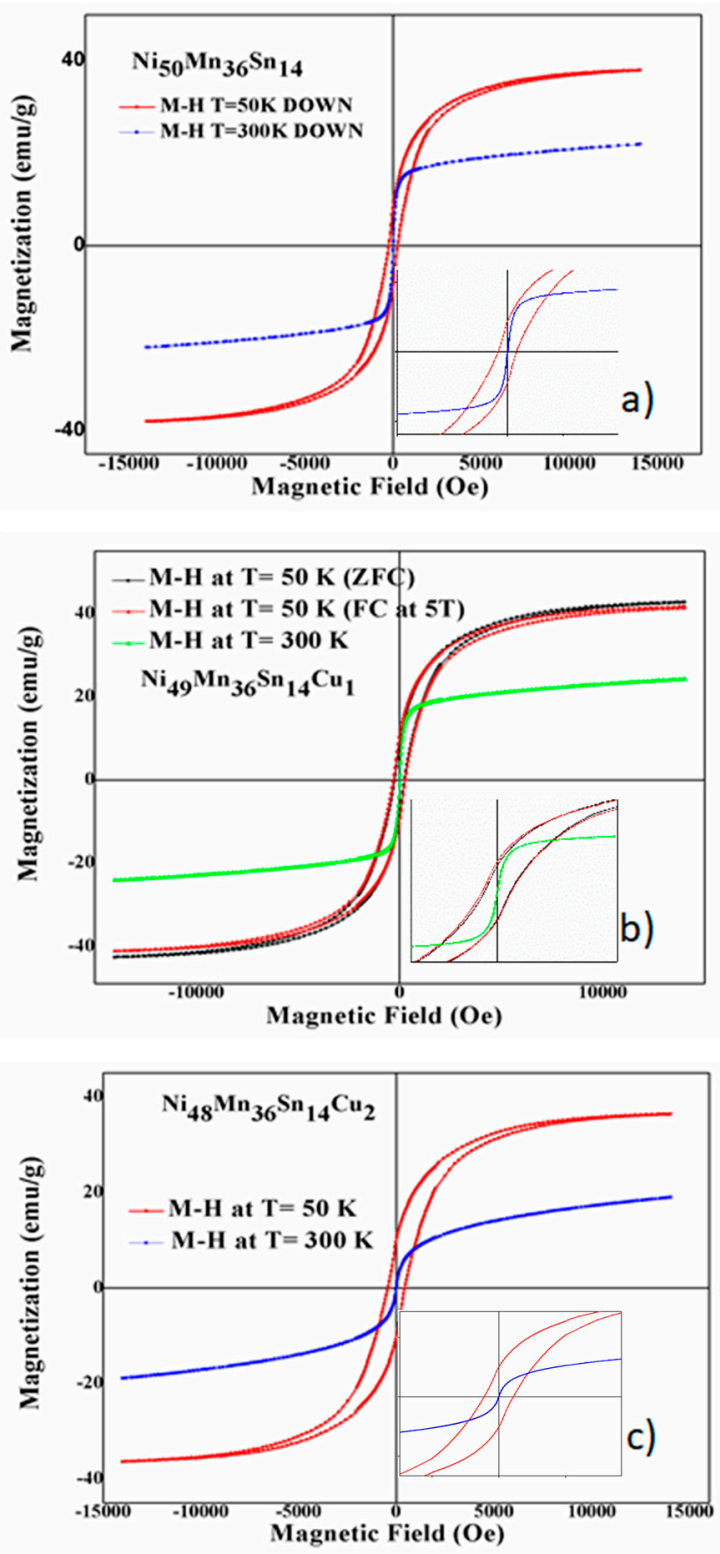

Figure 8. Magnetic hysteresis loops at room temperature of alloys: (a) $\mathrm{Ni}_{50} \mathrm{Mn}_{36} \mathrm{Sn}_{14}$, (b) $\mathrm{Ni}_{49} \mathrm{Mn}_{36} \mathrm{Sn}_{14} \mathrm{Cu}_{\mathrm{a}}$ and (c) $\mathrm{Ni}_{48} \mathrm{Mn}_{36} \mathrm{Sn}_{14} \mathrm{Cu}_{2}$.

\section{Conclusions}

Three alloys with nominal composition (at.\%) $\mathrm{Ni}_{50-x} \mathrm{Mn}_{36} \mathrm{Sn}_{14} \mathrm{Cu}_{\mathrm{x}}(x=0,1$, and 2) were produced by melt-pinning as ribbon flakes. At room temperature all the samples have the austenite $\mathrm{L} 2_{1}$ cubic Heusler structure. The $\mathrm{L} 2_{1}$ order parameter decreases after cycling to values ranged between $73-75 \%$. Thermal analysis detects the reversible structural transformation, $\mathrm{Cu}$ addition shifts this transformation to higher temperature. After thermal cycling (100 cycles) it was found a slight increase of the Gibbs equilibrium temperature of the structural transformation, this shift is reduced in the thermomagnetic scans at $50 \mathrm{kOe}$. Whereas the Curie temperature remains close to $310 \mathrm{~K}$. The calculated magnetization/entropy change ratios were 1.10, 1.30 and $1.16 \mathrm{~K} / \mathrm{T}$ for the alloys with $\mathrm{x}=0$, 1 , and 2 at. $\%$ of $\mathrm{Cu}$, respectively. Results show the interest to check the thermal stability and the magnetic response of these alloys due to the cycling working conditions linked to some of their specific applications and also the interest of $\mathrm{Cu}$ addition to shift the transition temperatures. 
Author Contributions: Conceptualization, J.-J.S. and M.K.; methodology, J.-M.G. and M.I.; formal analysis, A.W.; investigation, A.W. and M.I.; data curation, J.-M.G. and M.K.; writing-original draft preparation, J.-J.S. and M.I. All authors have read and agreed to the published version of the manuscript.

Funding: This study was funded by University of Girona PONT2020-01 and Spanish Mineco MAT201675967-P projects.

Data Availability Statement: Data can be requested from the authors.

Acknowledgments: The authors would like to thank the members of the Research Services (STR) of the University of Girona and the SGIker laboratory of the University of the Basque Country for their assistance and support in the analysis of the composites.

Conflicts of Interest: The authors declare no conflict of interest.

\section{References}

1. Czaja, P.; Przewoznik, J.; Fitta, M. Heat treatment effect on the evolution of magnetic properties of martensite in magnetic shape memory $\mathrm{Ni}_{48} \mathrm{Mn}_{39.5} \mathrm{Sn}_{9.5} \mathrm{Al}_{3}$ Heusler alloy ribbons. Mater. Res. Bull. 2021, 135, 111120. [CrossRef]

2. Navarro-García, J.D.; Llamazares, J.L.S.; Camarillo-García, J.P. Synthesis of highly dense spark plasma sintered magnetocaloric Ni-Mn-Sn alloys from melt spun ribbons. Mater. Lett. 2021, 195, 129857. [CrossRef]

3. Chabri, T.; Ghosh, K.; Mukherjee, D.; Nath, T.K. Role of interplay of austenite and martensite phase fractions on the magnetocaloric and magnetoresistance effects across the martensite transition in $\mathrm{Ni}_{45} \mathrm{Mn}_{44} \mathrm{Sn}_{7} \mathrm{In}_{4}$ Heysler alloy near room temperature. J. Appl. Phys. 2020, 128, 215106. [CrossRef]

4. $\quad$ Ling, Y.C.; Hu, Y.; Wang, H.B.; Niu, B.; Chen, J.W.; Liu, R.B.; Yuan, Y.; Wang, G.Y.; Wu, D.; Xu, M.X.; et al. Strain control of phase transition and exchange bias in flexible Heusler alloy thin films. ACS Appl. Mater. Interface 2021, 13, 24285-24294. [CrossRef] [PubMed]

5. El-Khatib, S.; Bhatti, K.P.; Srivastava, V.; James, R.D.; Leighton, C. Nanoscale magnetic phase competition throughout the $\mathrm{Ni}_{50-\mathrm{x}} \mathrm{Co}_{\mathrm{x}} \mathrm{Mn}_{40} \mathrm{Sn}_{10}$ phase diagram: Insights from small angle neutron scattering. Phys. Rev. Mater. 2019, 3, 104413. [CrossRef]

6. Shen, Y.; Wei, Z.Y.; Shen, Q.; Zhang, Y.F.; Liu, J. Orientation dependent elastocaloric effect in directionally solidified Ni-Mn-Sn alloys. Scrip. Mat. 2019, 163, 14-18. [CrossRef]

7. Louidi, S.; Suñol, J.J.; Ipatov, M.; Hernando, B. Effect of Co doping on martensitic transformations and the magnetic properties of $\mathrm{Ni}_{50-\mathrm{x}} \mathrm{Co}_{\mathrm{x}} \mathrm{Mn}_{37} \mathrm{Sn}_{13}(\mathrm{x}=1,2,3)$ Heusler ribbons. J. Alloys Comp. 2018, 739, 305-310. [CrossRef]

8. Khan, M.; Jung, J.; Stoyko, S.S.; Mar, A.; Quetz, A.; Samanta, T.; Dubenko, I.; Ali, N.; Stadler, S.; Chow, K.H. The role of Ni-Mn hybridization on the martensitic phase transitions in Mn-rich Heusler alloys. App. Phys. Lett. 2012, 100, 172403. [CrossRef]

9. Bachaga, T.; Zhang, J.; Khitouni, M.; Suñol, J.J. NiMn-based Heusler magnetic shape memory alloys: A review. Inter. J. Adv. Manuf. Tech. 2019, 103, 2761-2772. [CrossRef]

10. Deltell, A.; El-Moez, A.A.M.; Álvarez-Alonso, P.; Ipatov, M.; Andrés, J.P.; González, J.A.; Sánchez, T.; Zhukov, A.; Escoda, M.L.; Suñol, J.J.; et al. Martensitic transformation, magnetic and magnetocaloric properties of NiMnFeSn Heusler ribbons. J. Mater. Res. Tech. 2021, 12, 1091-1103. [CrossRef]

11. Unzueta, I.; López-García, J.; Sánchez-Alarcos, V.; Recarte, V.; Pérez-Landazabal, J.I.; Rodríguez-Velamazán, J.A.; Garitaonandia, J.S.; Garcia, J.A.; Plazaola, F. Testing the applicability of Sn 119 Mössbauer spectroscopy for the internal stress study in ternary and Co doped Ni-Mn-Sn metamagnetic alloys. Metals 2021, 11, 450. [CrossRef]

12. Wang, L.B.; Xuan, H.C.; Liu, S.L.; Cao, T.; Xie, Z.G.; Liang, X.H.; Chen, F.H.; Zhang, K.W.; Feng, L.; Han, P.D.; et al. Enhanced elastocaloric effect and mechanical properties of Gd-doped Ni-Mn-Sn-Gd ferromagnetic shape memory alloys. J. Alloys Comp. 2020, 846, 156313. [CrossRef]

13. Dadda, K.; Alleg, S.; Suñol, J.J.; Bessais, L.; Hlil, E.K. Structure, magnetocaloric effect and critical behavior in $\mathrm{Ni}_{50} \mathrm{Mn}_{30}\left(\mathrm{Sn}_{2} \mathrm{In}_{20}\right.$ Heusler alloys. J. Super. Nov. Magn. 2020, 33, 2209-2218. [CrossRef]

14. Varzaneh, A.G.; Kameli, P.; Sarsari, I.A.; Zavareh, M.G.; Mejia, C.S.; Amiri, T.; Skorski, Y.; Luo, J.L.; Etsell, T.H.; Chernenko, V.A. Magnetic and magnetocaloric properties of $\mathrm{Ni}_{47} \mathrm{Mn}_{40} \mathrm{Sn}_{13-\mathrm{x}} \mathrm{Zn}_{\mathrm{x}}$ alloys: Direct measurements and first-principles calculations. Phys. Rev. B 2020, 101, 134403. [CrossRef]

15. Villa, E.; Maziarz, W.; Wojcik, A.; Nespoli, A.; Lazpita, P.; Hosoda, H.; Chernenko, V. Martensitic transformation and structural states in $\mathrm{Ni}_{44.0} \mathrm{Mn}_{43.5} \mathrm{Sn}_{12.5-\mathrm{x}} \mathrm{Al}_{\mathrm{x}}(\mathrm{x}=1,2,3$ at.\%) magnetic shape memory alloys prepared by vacuum hot pressing. J. Alloys Comp. 2020, 847, 156315. [CrossRef]

16. Wederni, A.; Ipatov, M.; Pineda, L.; Escoda, L.; González, J.M.; Khitouni, M.; Suñol, J.J. Martensitic transformation, thermal analysis and magnetocaloric properties of Ni-Mn-Sn-Pd alloys. Processes 2020, 8, 1582. [CrossRef]

17. Kirat, G.; Aksan, M.A. Investigation of martensitic transformation and magnetoresistance properties of Cu substituted Ni-Mn-Sn-B melt spun ribbons. J. Magn. Magn. Mater. 2021, 529, 167858. [CrossRef]

18. Han, B.L.; Tan, C.L.; Zhao, L.; Zhao, W.B.; Ma, T.Y.; Wang, C.; Zhang, K.; Tian, X.H. Investigation on phase structure and magnetic properties of high-temperature Ni-Pt-Co-Mn-Sn magnetic shape memory alloys by first-principles calculations. Comp. Mater. Sci. 2021, 199, 110748. [CrossRef] 
19. Qu, Y.; Gràcia-Condal, A.; Mañosa, L.; Planes, A.; Cong, D.; Nie, Z.; Ren, Y.; Wang, Y. Outstanding caloric performances for energy-efficient multicaloric cooling in a Ni-Mn based multifunctional alloy. Acta Mater. 2019, 177, 46-55. [CrossRef]

20. Wederni, A.; Ipatov, M.; Pineda, E.; Suñol, J.J.; Escoda, L.; González, J.M.; Alleg, S.; Khitouni, M.; Zuberek, R.; Chumak, O.; et al. Magnetic properties, martensitic and magnetostructural transformations of ferromagnetic Ni-Mn-Sn-Cu shape memory alloys. Appl. Phys. A 2020, 126, 320. [CrossRef]

21. Coll, R.; Saurina, J.; Escoda, L.; Suñol, J.J. Thermal analysis of $\mathrm{Mn}_{50} \mathrm{Ni}_{50-\mathrm{x}}(\mathrm{Sn}, \mathrm{In})_{\mathrm{x}}$ Heusler shape memory alloys. J. Therm. Anal. Calorim. 2018, 134, 1277-1284. [CrossRef]

22. Wang, H.; Zhang, H.; Tan, Y.W.; Huo, D. Spin glass feature and exchange bias effect in metallic Pt/antiferromagnetic LaMnO 3 heterostructure. J. Phys. Condens. Matter. 2021, 33, 285802. [CrossRef] [PubMed]

23. Zhang, K.; Tian, X.; Tan, C.; Guo, E.; Zhao, W.; Cai, W. Designing a new Ni-Mn-Sn-Fe ferromagnetic shape memory alloy with excellent performance by $\mathrm{Cu}$ addition. Metals 2018, 8, 152. [CrossRef]

24. Yuzuak, E. The magnetothermal characterization of Ni-Cu-Mn-Sn alloy. Mater. Res. Bull. 2021, 142, 111398. [CrossRef]

25. Castillo-Villa, P.O.; Mañosa, L.; Planes, A.; Boto-Parra, D.E.; Sánchez-Llamazares, J.L.; Flores-Zúñiga, H.; Frontera, C. Elastocaloric and magnetocaloric effects in Ni-Mn-Sn(Cu) shape memory alloy. J. Appl. Phys. 2013, 113, 053506. [CrossRef] 